\title{
BMJ Open Respiratory Research \\ Respiratory physiology and exercise science: time to bridge the gap?
}

\author{
Oliver J Price, ${ }^{\oplus 1}$ Karl P Sylvester, ${ }^{2}$ James H Hull ${ }^{\circledR}$
}

To cite: Price 0J, Sylvester KP, Hull JH. Respiratory physiology and exercise science: time to bridge the gap?. BMJ Open Resp Res 2019;6:e000442. doi:10.1136/ bmjresp-2019-000442

Received 24 April 2019 Accepted 26 April 2019

Check for updates

C Author(s) (or their employer(s)) 2019. Re-use permitted under CC BY-NC. No commercial re-use. See rights and permissions. Published by BMJ.

${ }^{1}$ Carnegie School of Sport, Leeds Beckett University, Leeds, West Yorkshire, UK ${ }^{2}$ Lung Function Department, Addenbrooke's Hospital, Cambridge, UK

${ }^{3}$ Department of Respiratory Medicine, Royal Brompton and Harefield NHS Foundation Trust, London, UK

Correspondence to Dr Oliver J Price; o.price@leedsbeckett.ac.uk
Respiratory disease effects one in five people and is a leading cause of morbidity and mortality in the UK. ${ }^{1}$ In response to increasing prevalence and rising associated $\operatorname{costs}^{2}$ - the Taskforce for Lung Health was established to deliver a 5-year plan or roadmap to improve respiratory health in England, ${ }^{3}$ as a priority as part of the National Health Service (NHS) England long-term plan. ${ }^{4}$ The Taskforce report, published in late 2018, provides a framework focusing on the importance of prevention, early and accurate diagnosis, high-quality treatments and support, and the recruitment of a highly knowledgeable and skilled workforce. ${ }^{3}$ The latter objective is perhaps most significant given staff shortages remain apparent across all levels of respiratory healthcare. ${ }^{5}$

In this context, it is alarming that the UK professional body for respiratory physiology practitioners-the Association for Respiratory Technology and Physiology (ARTP) recently published findings from a nationwide survey confirming that a substantial shortfall exists in the quantity of trained respiratory physiologists across the NHS. ${ }^{6}$ Indeed, respiratory physiology has been registered on the UK shortage occupations list for over a decade ${ }^{7}-$ suggesting either a lack of awareness or interest when compared with other areas of healthcare science. This is clearly concerning given physiological measurement remains the bedrock of diagnosis in respiratory disease and quality-assured measurement is vital to ensure accurate and timely diagnosis. Indeed, the vast majority of diagnostic and surveillance pathways in respiratory medicine are completely dependent on the delivery of high-quality physiological measurement.

It is, thus, essential that an adequate workforce is supported in order to accurately diagnose, monitor and exclude lung disease, and in turn, optimise the level and quality of care received. ${ }^{3}$ Although Taskforce investment targets to create 500 additional respiratory physiology training posts are welcome, ${ }^{3}$ it currently takes $4-5$ years to train a respiratory physiologist via an undergraduate taught programme and to provide on-the-job practical skills training. Thus, there remains an immediate shortfall to support clinical assessment provision and to provide suitable training and education to the upcoming future workforce. Taken together, this begs the question(s): (1) who is suitability qualified to fill the current shortfall in respiratory physiology posts over the next 5 years? and (2) how do we appeal and promote a career in respiratory medicine to the most promising prospective candidates?

One solution is to consider if more can be done to recruit trainees from other physiology backgrounds. In this respect, approximately 15000 students graduate with a degree in sport and exercise science each year. ${ }^{8}$ However, a common misconception is that exercise science focuses primarily on 'sporting' performance, and thus prospective employers (notably across healthcare science and medicine) often fail to recognise the relevance or wider applicability of the qualification. In reality, exercise science, at least from a physiological perspective, centres on understanding the integration of neurological, respiratory, cardiovascular, muscular and skeletal systems, at rest and during exercise in both health and disease. Training includes the development of sought-after clinically relevant practical skills, including but not limited to exercise testing, lung function and cardiovascular measurement.

The British Association of Sport and Exercise Sciences (BASES) (UK professional body) has previously highlighted a growing need to recognise and incorporate exercise scientists into the NHS and public health settings. ${ }^{9}$ However, despite clear transferability between disciplines (particularly for students electing clinical physiology modules and/ or completing postgraduate study), assured voluntary registers such as the Registration Council for Clinical Physiologists (RCCP) do not currently accept exercise science via the 'accreditation of prior learning' pathway. ${ }^{10}$ Specific to respiratory medicine, the majority of advertised entry-level clinical physiologist 
posts in the NHS (ie, at band 4-5 level) currently stipulate that a degree in healthcare or physiological sciences (often with advanced ARTP practitioner competency qualifications and RCCP registration) is an essential entry criteria, and more often than not, fail to acknowledge related or equivalent degrees. A recognised pathway for exercise science graduates aspiring to begin a career in respiratory physiology has, therefore, yet to be firmly established or supported, which almost certainly acts to deter promising candidates from applying to vacant posts, and in turn, fails to address growing workforce shortages (variety of personal communications).

Although some practitioners may hold the opinion that recruiting applicants from 'non-traditional' or non-accredited pathways may have a deleterious impact on professional standards-the rigorous training that is undertaken in most clinical lung function units including mentorship from senior, experienced colleagues and early promotion of professional qualifications actually ensures best practice is upheld and maintained. Furthermore, it could be argued that candidates entering from an exercise science background are actually better placed to advise and educate patients on the importance of adjunctive non-pharmacological treatments (eg, structured exercise, physical activity promotion and nutrition) and would create a working environment conducive to mutual knowledge transfer and permit a multidisciplinary team approach to patient care, that is, align directly with Task Force and NHS long-term plan objectives. ${ }^{34}$

It is thus the authors' opinion that the aforementioned evidence provides a strong case to 'bridge the gap' between respiratory physiology and exercise science in order to build future workforce capacity and alleviate growing pressure on diagnostic support services. We therefore extend a 'call-to-action' to NHS policy decision-makers to revise entry-level career frameworks and establish an official exercise science graduate entry respiratory healthcare pathway. The development of educational partnerships between higher education institutions and existing professional bodies (ARTP, BASES, and RCCP) is a logical first-step in achieving this objective.

Contributors All authors contributed to the preparation of this manuscript.

Funding This research received no specific grant from any funding agency in the public, commercial or not-for-profit sectors.

Competing interests None declared.

Patient consent for publication Not required.

Provenance and peer review Commissioned; internally peer reviewed.

Open access This is an open access article distributed in accordance with the Creative Commons Attribution Non Commercial (CC BY-NC 4.0) license, which permits others to distribute, remix, adapt, build upon this work non-commercially, and license their derivative works on different terms, provided the original work is properly cited, appropriate credit is given, any changes made indicated, and the use is non-commercial. See: http://creativecommons.org/licenses/by-nc/4.0/.

\section{REFERENCES}

1. Public Health England. Respiratory disease: applying all our health, 2015. Available: https://www.gov.uk/government/ publications/respiratory-disease-applying-all-our-health/respiratorydiseaseapplying-all-our-health

2. British Lung Foundation. The battle for breath - the economic burden of lung disease, 2016. Available: https://www.blf.org.uk/ policy/economic-burden

3. Task Force Report, 2018. Available: https://www.blf.org.uk/taskforce/ plan

4. The NHS long term plan, 2019. Available: https://www.longtermplan. nhs.uk/

5. The Lancet Respiratory Medicine. NHS staff shortages threaten the future of respiratory health. Lancet Respir Med 2019;7.

6. Association of Respiratory Technology and Physiology Workforce \& Staffing Survey, 2018. Available: http://www.artp.org.uk/en/aboutartp/artp-reports.cfm/Workforce-Survey-2018

7. UK Shortage Occupations List, 2019. Available: http://www. visabureau.com/uk/shortage-occupations-list.aspx

8. Higher Education Statistics Agency, 2019. Available: https://www. hesa.ac.uk/data-and-analysis/students/table-19

9. A guide to employing sport and exercise graduates in the NHS and public health. Available: https://www.bases.org.uk/imgs/nhs_leaflet_ final267.pdf

10. The Regsitration Council for Clincial Physiologists Accredication of prior learning. Available: https://www.rccp.co.uk/documents/9a.\% 20RCCP\%20Accreditation\%20of\%20Prior\%20Learning1.pdf 